\title{
Insurance research and medical ethics
}

\author{
Lorie Terry
}

$\mathrm{O}^{n}$ n January 1, 1995, Saskatchewan adopted a radical, no-fault system for motor vehicle accident insurance. Virtually no room was left for injured victims to sue for damages, whether for pain and suffering or for economic compensation. In fact, the no-fault system removed benefits for pain and suffering altogether. Apart from the concern that arose at the denial of justice in relation to economic matters and the blanket denial of pain, there was concern over the arrangements for medical care. Under the new Automobile Accident Insurance Act, injured persons were entitled to compensation and payment for treatment, as managed by their own doctors, chiropractors or physiotherapists for the first six weeks subsequent to an injury. Thereafter, they were required to be seen by insurance company-appointed doctors, chiropractors or physiotherapists if they wished the income replacement benefits to continue, treatment to be provided or both. They also were obliged to accept the recommendations of the insurance company doctors for the next 12 weeks, under what was called 'secondary rehabilitation'. If they claimed not to be well at the end of that period, further rehabilitation, described as 'tertiary rehabilitation' would be ordered. Two specific 'inpatient' centres were established for tertiary rehabilitation in different parts of the province (Regina and Saskatoon), and victims thought to be in need of tertiary rehabilitation had to travel if they did not live in either Regina (the provincial capital) or Saskatoon. The administration and treatment of individuals under these systems were so unacceptable to many individuals that a widespread resistance movement was generated and was established as the Coalition Against No-Fault Insurance on August 28, 1998, opening with simultaneous protests in Regina, Saskatoon,
Prince Albert North Battleford and Estevan, each one organized by a local victim of the no-fault insurance scheme.

Many citizens of Saskatchewan, who do not usually participate in protest movements, gave their sympathy and support, including members of the Royal Canadian Mounted Police detachment in Prince Albert (its members who worked on the roads were often affected by treatment of their claims for injury) and other police personnel, as well as a large number of citizens from many different occupations, whose income had been substantially affected while they were unable to work. A joint no-fault committee comprising the Saskatchewan branch of the Canadian Bar Association, the Saskatchewan Trial Lawyers Association and the Law Society of Saskatchewan also supported the Coalition.

\section{A PROPOSED INCEPTION COHORT STUDY OF TRAFFIC INJURIES IN SASKATCHEWAN (PICSTIS)}

The first results of the new policy were described in a paper published in The New England Journal of Medicine in April 2000 (1). According to this article, which used claim closure by the insurance company as its principal measure of recovery, the victims who had received treatment under the new system recovered twice as fast - ie, in an average of 203 days - as the individuals who in previous years had been treated under the tort system, who took an average of 433 days to heal. As well, it was alleged that pain and suffering were reduced by the new arrangement and that depression and pain improved twice as quickly under the new system as under the old one. 
The paper by Cassidy et al (1) was vigorously attacked on the grounds that the use of claim closure as a measure of recovery was not supported either by the literature or by adequate data on the symptoms, treatment or degree of functional impairment of the injured subjects. Changes in the levels of pain and depression recorded in the study subjects were not presented with the data in the article (2). Merskey and Teasell (3) objected to the failure of the original investigators to include $28 \%$ of all the subjects, because their claims had been closed and then 're-opened' and adequate information was, therefore, said not to be available. Dr Robert S Russell, a family practitioner in Saskatchewan, noted that among his patients, those whose claims had been closed by Saskatchewan Government Insurance (SGI) had not recovered, in his opinion (4). He also reported signifiant data to a public review committee commissioned to review the no-fault legislation in the summer of 2000 (5). Russell (5) conducted a poll of physicians with the results showing that,

...in regards to whiplash, 72.7 percent of physicians felt that some of these assessments and treatments provided by these treatment centres are inappropriate and unnecessary. This increases to 81.8 percent or 82 percent for those more experienced physicians that reported having seven or more patients a year in a treatment centre for the last year and see the majority of all whiplash injuries ... Physicians are also frustrated by their inability to intervene in their patient's treatment, especially if their patient's condition is being aggravated or worsened by the treatment received at the treatment centre. Almost half felt that overall they could not intervene in a meaningful way on behalf of their patients.

Ms Kathy Kivol, a retired adjuster, reported that she was very surprised by the claim that Cassidy et al (1) could not find the original date of closure of a claim if the claim was closed and then re-opened, because she had always kept such information on her computer (6). Additional details of the foregoing arguments concerning the inadequate quality of the study in The New England Journal of Medicine are given by Merskey et al (7).

The study reported in The New England Journal of Medicine was funded by SGI. The original protocol of the agreement between the University of Saskatchewan and SGI allowed the insurance company to terminate the study (to which it was committing $\$ 1$ million) at any time. As well, in a phase of the study where differences of opinion arose between the original principal investigator, Dr Ken Yong-Hing, and the insurance company, Dr Yong-Hing was summarily removed from his post as principal investigator, at the request of the insurance company to the university. Dr Yong-Hing made known this change to the Trial Lawyers Association of Saskatchewan in a letter dated November 12, 1996, addressed to Mr Colin Clackson, who was president of the association at that time. Subsequently, a letter became available to the coalition, confirming Dr Yong-Hing's report with stark brevity. The letter was addressed to Dr David Popkin, Dean of the College of Medicine, at the University of Saskatchewan, dated June 11, 1966 (sic), and read as follows:

Dear Dr Popkin:
I am asking your permission for the princip
investigator for the cohort agreement to be
from Dr K Yong-Hing to Dr David Cassidy
June 11, 1996, at 11:30 am. I look forward
continued work with the university and Dr.
Yours truly,
Doreen Leslie [signature] for Jon Schubert,
Assistant Vice-President,
Injury Claims and Rehabilitation.

Copies of this letter were also sent by Mr Schubert to the Assistant Dean for Research at the College of Medicine, at the University of Saskatchewan, and to the Associate VicePresident, Research Administration.

I understand that the existence of a contract that allowed so much interference by a sponsor from industry is in complete contrast to the recommendations of the Canadian Medical Association for research that is performed in association with industry (8). The recommendations require that grants be unrestricted, implying that there can be no interference in such a serious matter as the subsequent removal and replacement of a principal investigator at the behest of a company of any sort - whether pharmaceutical or insurance.

As well, it is on record that Dr Emma Bartfay started work at the University of Saskatchewan as an Assistant Professor of Epidemiology commencing March 1, 1998. She was appointed to assist Dr Cassidy in the statistical evaluation of the data that were later published in The New England Journal of Medicine. Dr Bartfay resigned her post on November 13, 1998 and subsequently (May 10, 1999) brought a lawsuit against the University of Saskatchewan and Dr Cassidy, alleging in the pleadings of her case as follows (9):

...in or about September 1998, and contrary to all normal and appropriate practices and procedures in regards to independent medical research, she was instructed by Cassidy to produce certain statistical results that would support the end conclusion that he desired. Specifically, the Plaintiff says that Cassidy instructed her to produce results and graphs that would support the conclusion that an injured person's time (date) of settlement is a good proxy for the person's time (date) of recovery.

The Plaintiff says that she advised Cassidy that in her professional opinion, the conclusion that Cassidy wanted was a matter of opinion and not fact, and that it would be inappropriate and contrary to sound 
practices of statistical research to purport, to show and portray such a conclusion as a matter of fact. In any case, the Plaintiff, says that to draw such conclusions within the ambit of the PICSTIS project could be problematic as the data that had been collected were not sufficient to handle the proposed or hypothesized relationship...

The Plaintiff says that she refused to do what was unethical and contrary to her professional standards and responsibility and as a consequence, she was treated with hostility, verbal abuse, insults, harassment and intimidation by the Defendant, primarily by its employees... The Plaintiff says that such unwarranted and unjustifiable treatment created an intolerable working environment.

It should be noted that these are allegations and not proven facts, and that the case is still before the Court of Queen's Bench for Saskatchewan.

Against this background of apparantly dubious science, a seemingly misleading publication from a source supported by SGI, the possible failure to observe appropriate rules for industry and serious dissent among the investigators, the Coalition Against No-Fault challenges the ethics of a further study at the University of Saskatchewan, a study that involves forcing poorly informed accident victims into giving their consent for private data about them to be compiled and handed over to the University of Saskatchewan for research purposes.

\section{THE OUTCOMES ASSESSMENT OF TREATMENT AND REHABILITATION AFTER TRAFFIC INJURIES IN SASKATCHEWAN (THE OUTCOMES STUDY)}

The original study discussed above (1) was entitled "A Proposed Inception Cohort Study of Traffic Injuries in Saskatchewan". A follow-up study was labelled the 'Outcomes Study'. We have now received information regarding the second study that has yet to be published. The available evidence indicates that this study is intended to show that certain treatments promoted by SGI are likely to be helpful to injured persons (10). The treatments consist of vigorous exercise for patients with whiplash and low back complaints; according to SGI, the Quebec Task Force (QTF) found that vigorous activity is the only treatment that produces recovery (9).

The study in question, not yet published, evaluated the treatment centres that SGI had set up for 'rehabilitation', based on the alleged QTF findings. According to the protocol of Cassidy et al (1), the purpose of the project was to assess the effectiveness of clinical interventions offered to people injured in traffic accidents in Saskatchewan, following the recent change in the insurance system from tort to no-fault, in January 1995.

\author{
SGI developed an intervention strategy based on the \\ recommendations of the Quebec Task Force on \\ whiplash-associated disorders, to which this \\ applicant, was a primary contributor.
}

As mentioned, the Outcomes Study protocol recommended that primary care was to be delivered under this strategy by general practitioners, chiropractors and physiotherapists for up to six weeks following injury. Nine centres across the province offered various forms of secondary intervention, and if a claimant failed to show improvement under secondary care by approximately 18 weeks after the collision (ie, six weeks in his or her doctor's care and 12 weeks in secondary care), he or she was to be directed to a tertiary level of intervention. Tertiary intervention would include a 30 day inpatient program, emphasizing occupational therapy, vocational training, psychosocial counselling, and therapy and work hardening, in addition to other traditional forms of treatment. According to the protocol for the study (11):
... as part of implementing this intervention program, SGI has requested that the Institute for Health and Outcomes Research provide an outcomes evaluation of this program. This will involve a province-wide follow-up of all claimants at all intervention levels for a period of 1 year.

The Outcomes Study was based on a serious misstatement. The QTF only found that normal activity was better than bedrest, which was well known. SGI then went on to sponsor facilities at "FIT For Active Living" in Saskatoon and Wascanna Rehabilitation Centre in Regina, which led to very unsatisfactory treatment of patients.

I can testify from personal experience that individuals were forced to undertake preposterous and agonizing tasks. One schedule required patients to carry pails of cement, pull bags of sand, push carts of bricks, climb up and down old stadium stairs repeatedly, rake gravel, drive screws into old metal frameworks above their heads and below their waists, and lift boxes with increasing amounts of weight each day.

Even if SGI had the legal right to coerce individuals into this horrible treatment, it was medically useless and often counterproductive, making some individuals worse for days, weeks and even months. Some victims appear to have realistic claims that their conditions were made permanently worse.

Many people gave up their claims or were cut off due to noncompliance when they were unable to meet the exercise demands. Some who persisted vomited repeatedly as their pain was made worse. Those entering this program in 1997 were obliged to sign an Application for Benefits Form, which was the last page of a more than 20-page booklet designed to gain information for SGI and the Institute for Health and Outcomes Research (IHOR). Once signed, the insurance company had full control over every aspect of the claimants life, and sections 1 through 4 forced the victim to comply under threat of losing all benefits, while the other 
sections of the application seem designed to eliminate most rights of privacy that the victim possessed. The Application for Benefits Form is provided in Appendix 1. Note especially paragraph 5 , sentence 1 :

I understand and agree that SGI may share the information regarding my claim for benefits with health care professionals, vocational rehabilitation professionals, Saskatchewan Social Services and the Institute for Health and Outcomes Research at the University of Saskatchewan.

Under the heading 'Procedures', the outcomes protocol states:

Claimants will complete an Application for Benefits Form when making a claim with SGI. This form was developed by SGI in consultation with IHOR and forms the basis for the claim for income replacement or funding for treatment with SGI. A copy of this form will be forwarded to the Institute for Health and Outcomes Research, and will be used to provide baseline information for this study. This form will have identifying information, addresses and phone numbers included.

In addition, those individuals attending treatment or rehabilitation programs designated by SGI as "secondary" and "tertiary" care programs will complete a 10-15 minute paper and pencil questionnaire at the beginning and at the end of their treatment program. These questionnaires will be administered by treatment program staff and forwarded to SGI and then to the Institute for Health and Outcomes Research

(emphasis added).

SGI was in the position to collect the data from both the paper and pencil questionnaires, and the initial database with identifiers before proceeding to send the information provided by claimants to the IHOR. The Application for Benefits Form designed by SGI was part of the data shared between SGI and IHOR, and was designed to give SGI information that should not have been available to an insurance company.

The World Health Medical Association Declaration of Helsinki (12) states:

When obtaining informed consent for the research project the physician should be particularly cautious if the subject is in a dependent relationship with the physician or may consent under duress. In that case the informed consent should be obtained by a well-informed physician who is not engaged in the investigation and who is completely independent of this relationship.

The pencil and paper interviews were to be collected before and after the victim entered the tertiary centres. Two further disturbing aspects of the data collection have been brought to light.
First, SGI was dictating how these data were to be completed and recovered from the centres conducting the rehabilitation mandated by SGI, thus putting the sponsor in full control of this process. Claimants were strongly encouraged to fill in the application for benefits on the spot, leaving no chance for legal consultation or contemplation. The following excerpt from a letter to John Murphy at the Canadian Back Institute, dated June 11, 1997, from Ms Lynn Henderson, Manager of the Personal Injury Protection Plan at SGI (who was also in the working group of the outcomes study) shows the aggressive nature of the collection of data.

The questionnaire should not take longer than 10 minutes to complete, and should be completed at your centre, rather than at home.

Second, this letter reveals that SGI had some direction over how the conduct of the study was applied by direct communication to therapists, whom it was paying. The application for ethics approval and the protocol of the outcomes study (under the heading 'confidentiality') specifically state:

Because of SGI's role in funding and directing treatments (SGI personnel serve as case managers for injured claimants), information gathered in the course of telephone and paper and pencil interviews will not be kept confidential from SGI.

We consider the forced consent to be a violation of medical ethics regarding experimentation on human subjects. Apart from it being morally repugnant to treat people in these ways, the claims form involved IHOR in a clear breach of the requirement in the Declaration of Helsinki that medical research should always be based on free and informed consent.

It stands out that the consent obtained was the result of coercion through the threat of loss of benefits. The Coalition is preparing a complaint to medical ethics authorities (particularly the Canadian Institutes for Health Research, which funds medical research in Canada) about this gross violation of medical ethics. The health care professionals involved in obtaining data on their patients for use in this way also had a conflict of interest, which they may or may not have recognized.

As well, victims were only partly informed about what was to be done with the information collected by SGI and given to IHOR. There is good reason to think that these cruel regimens were likely to be used to 'prove' (through claim closure) that such ill treatment was positively beneficial. Further, all medical research in Canada is expected to include in its consent form a statement that the subject (patient) is free to terminate participation in the research at any time, without prejudice to their future care. This notion does not appear to have been part of the SGI/IHOR agreement and seems distinctly foreign to the bureaucrats and investigators who implemented the IHOR outcomes study. 
The protocol of the outcomes study shows that the investigators were aware of ethical guidelines but decided to disregard what should have been an inherent procedure designed to protect research subjects from abuses of power. Instinct would tell most people that the following excerpt of the protocol is wrong and that it would be very surprising for a properly informed ethics review board to allow the procedures described.

This study has been approved by the University of Saskatchewan Advisory Committee on Ethics in Human Experimentation. № consent is being requested from claimants. Because of its role in providing treatment and rehabilitation for claimants suffering traffic injuries and making personal injury claims, SGI has the legal right under the Act to collect information and to share that information with appropriate sources to ensure quality of care. The Freedom of Information agreement outlines the specifics of information sharing. Claimants sign the last page of the Application for Benefits, which states

that they may be contacted by researchers at the

University of Saskatchewan.

Even if SGI had the legal right (which may be questioned) to share such material as was collected with IHOR, IHOR was in gross violation of the requirements for ethical research in Canada and all other civilized countries. IHOR was not entitled ethically to receive information obtained coercively by SGI, and patients were not properly informed about what would be done with the data obtained in that fashion.

The above rehabilitation 'studies' have revictimized many claimants twice, in many cases causing undue psychological and physical trauma. The Coalition Against NoFault believes that the researchers and their work are in violation of medical ethics, and that they must be made accountable for their actions. The Coalition also feels that this type of research creates a 'slippery slope', allowing insurance and compensations boards to sponsor research by whatever means to gain the power that they need to influence public policy and perception.

\section{APPENDIX 1 \\ Application form of the Saskatchewan Government Insurance proposed in the Institute for Health and Outcomes Research protocol}

Institute for Health Outcomes Research

Protocol Manual: Outcomes Assessment

\section{IMPORTANT!! \\ PLEASE READ BEFORE YOU SIGN}

1. I am applying to Saskatchewan Government Insurance (SGI) for any compensation to which I may be entitled under the Automobile Accident Insurance Act (the Act) and Regulations.

2. The information on this form is true and correct in every respect and I agree to let my adjuster know right away if anything changes that may affect my claim, including any return to work or income earned from employment.

3. I understand that the Criminal Code makes it an offence, punishable by fine and/or imprisonment, to attempt to obtain money or property (including compensation or services under the Automobile Accident Insurance Act) by deceit, falsehood or other fraudulent means; and that anyone who does so is also liable to reimburse SGI, in full, for any payment obtained this way.

4. I understand that holding back information about income, interfering with or delaying my recovery or not cooperating with rehabilitation or with reasonable requests for medical examination may cause my benefits to be cut back or cancelled altogether.

5. I understand and agree that SGI may share the information regarding my claim for benefits with health care professionals, vocational rehabilitation professionals, Saskatchewan Social Services and the Institute for Health and Outcomes Research at the University of Saskatchewan. I further understand and agree to better facilitate the administration of my claim, medical or vocational information may be exchanged directly between health care professionals or vocational rehabilitation professionals, and I hereby authorize such direct exchange or provision of information.

6. I authorize SGI to undertake whatever investigations are necessary with respect to my claim for compensation, including examination of any medical and employment information that SGI deems as relevant.

SIGNED AT THIS DAY OF , 19

CLAIMANT/REPRESENTATIVE SIGNATURE

PRINT CLAIMANT'S NAME

WITNESS

WITNESS

Note: A photocopy of this form is to be accepted as if it were an original. 


\section{REFERENCES}

1. Cassidy JD, Carroll LJ, Coté P, Lemstra M, Berglund A, Nygren A. The effect of eliminating compensation for pain and suffering on the outcome of insurance claims for whiplash injury. N Engl J Med 2000;342:1179-86.

2. Freeman MD, Rossignol AM. The effect of eliminating compensation for pain and suffering on the outcome of insurance claims. N Engl J Med 2000;343:1118-9.

3. Merskey H, Teasell R. The effect of eliminating compensation for pain and suffering on the outcome of insurance claims. N Engl J Med 2000;343:1119.

4. Russell RS. The effect of eliminating compensation for pain and suffering on the outcome of insurance claims. N Engl J Med 2000;343:1119-20

5. Oral testimony by Dr Robert S Russell to the Personal Injury Protection Plan [PIPP] Review Committee, Saskatoon, June 15, 2000. <www.againstnofault.com> Version current at August $31,2000$.

6. Kivol K. Re: Saskatchewan Government Insurance study. Pain Res Manage 2000;5:129-30. (Lett)

7. Merskey H, Teasell R, Nussbaum D. Science, whiplash, insurance and minimizing pain. The Verdict 2001;90:46-9.

8. Canadian Medical Association Policy Summary: Physicians and the Pharmaceutical Industry (Update 1994). CMAJ 1994;150:256A-C.

9. Bartfay v Cassidy and the University of Saskatchewan, Ct QB \#1079, Para. 13-16, Saskatoon.

10. Report to the PIPP Review Committee by Saskatchewan Government Insurance 2000, <www.SGI.sk.ca>. Version current at May 30, 2000.

11. Cassidy JD, Carroll LJ, Coté P, Lemstra M, Berglund A, Nygren A. Investigative study protocol, The Outcomes Assessment of Treatment and Rehabilitation After Traffic Injuries in Saskatchewan ("The Outcomes Study"), Saskatoon: The Institute for Health and Outcomes Research, The University of Saskatchewan, 1997.

12. World Medical Association Declaration of Helsinki. Ethical Principles for Medical Research Involving Human Subjects. Adopted by the 18th WMA General Assembly Helsinki, Finland, June 1964 and amended by the 29th WMA General Assembly, Tokyo, Japan, October 1975; 35th WMA General Assembly, Venice, Italy, October 1983; 41st WMA General Assembly, Hong Kong, September 1989; 48th WMA General Assembly, Somerset West, Republic of South Africa, October 1996; and the 52nd WMA General Assembly, Edinburgh, Scotland, October 2000.

The views expressed in this editorial are those of the author and are not intended to reflect the opinions of the Canadian Pain Society or Pulsus Group Inc 


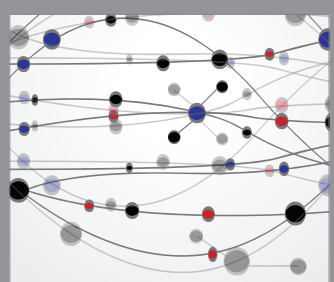

The Scientific World Journal
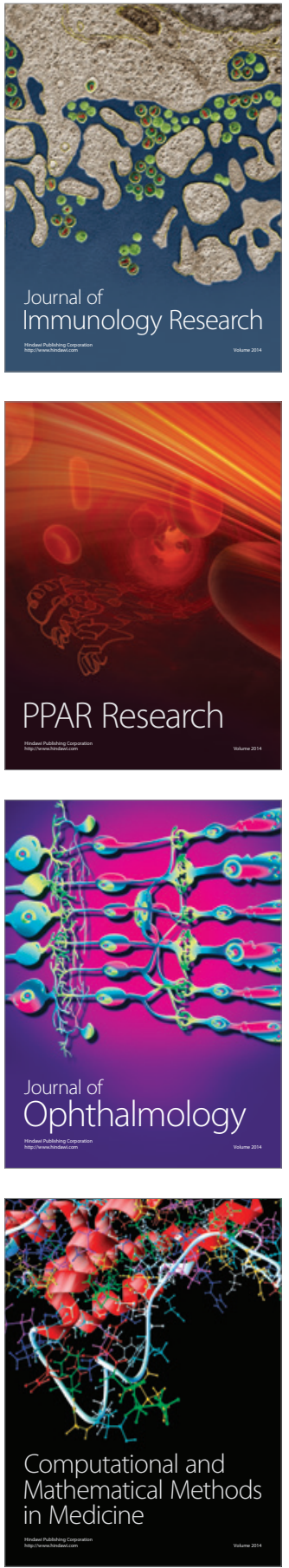

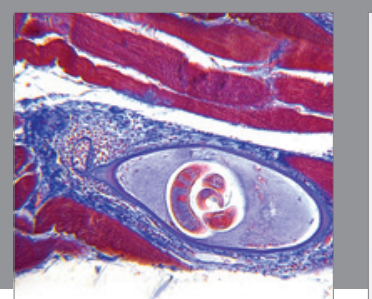

Gastroenterology Research and Practice

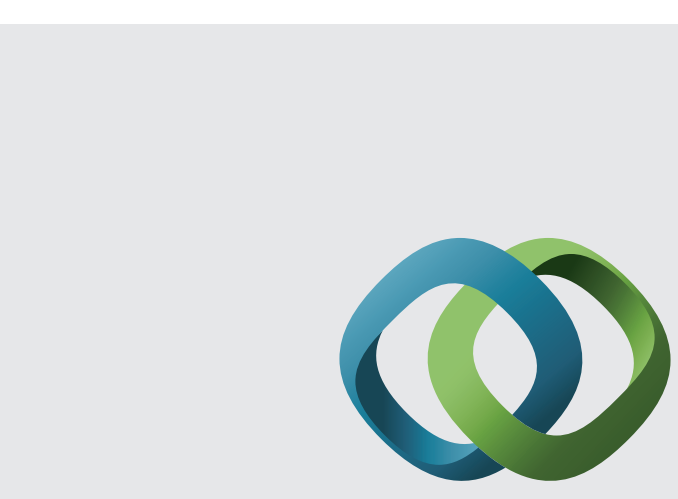

\section{Hindawi}

Submit your manuscripts at

http://www.hindawi.com
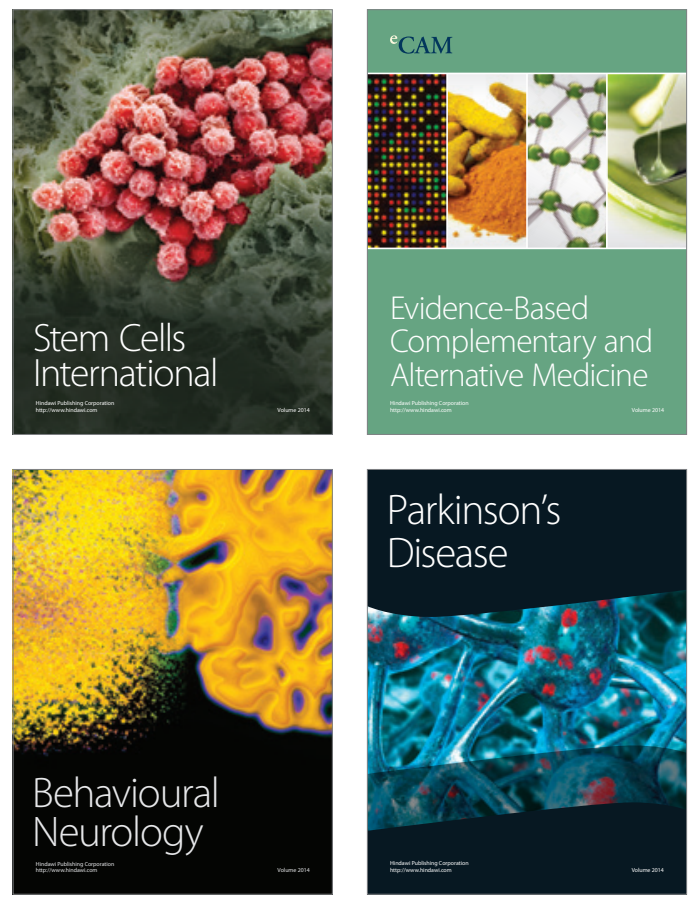
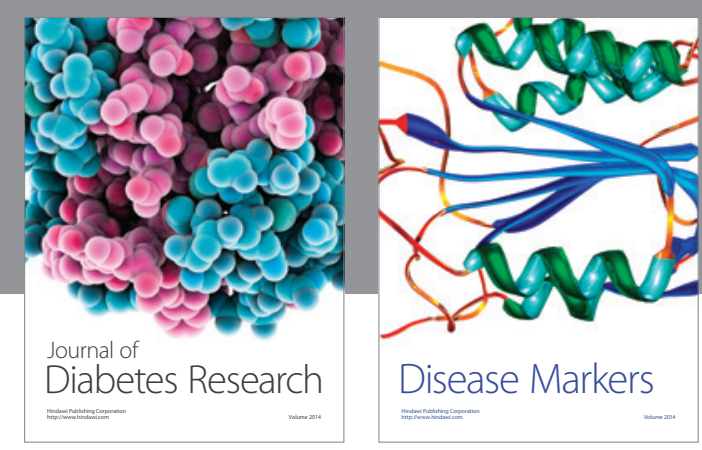

Disease Markers
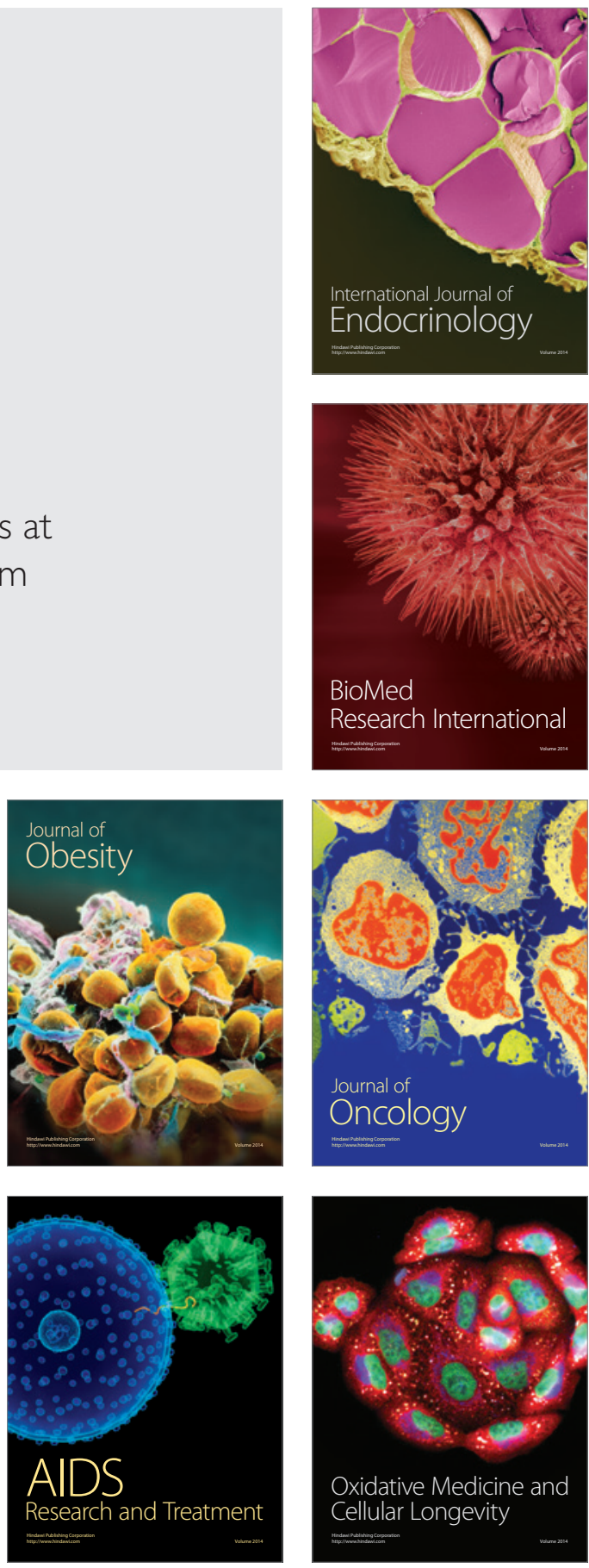